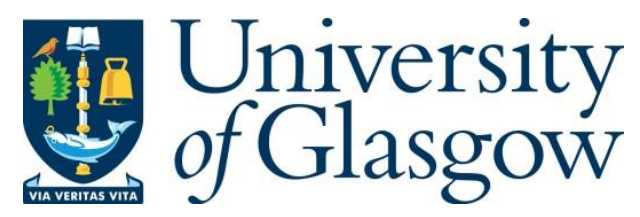

You, S., Li, W., Yan, W.-C. and Sonne, C. (2021) Green strategies for sustainable packaging. Science, 372(6544), p. 802.

There may be differences between this version and the published version. You are advised to consult the publisher's version if you wish to cite from it.

http://eprints.gla.ac.uk/242299/

Deposited on: 21 May 2021

Enlighten - Research publications by members of the University of Glasgow http://eprints.gla.ac.uk 


\section{Green strategies for sustainable packaging}

Packaging constitutes roughly $46 \%$ of global plastic waste (1). In the European Union, packaging waste increased by $9.4 \%$ (6.7 million metric tons) in the decade after 2008, reaching 77.7 million metric tons in 2018 (2). Globally, the total value of packaging was USD917 billion in 2019; it will likely increase to USD1.05 trillion by 2024 (3). Countries such as the United Kingdom and China are making an effort to curtail packaging waste, but to make real progress, governments must require the packaging industry to embrace more sustainable methods.

The United Kingdom generates more than 11 million metric tons of packaging waste each year despite a recycling and recovery rate of $70 \%$ (4). To reduce its packaging-related pollution and boost recycling and recovery, the United Kingdom launched a plastic packaging tax, under which manufacturers and importers are charged USD277 per ton when using packaging with less than $30 \%$ recycled plastic (5). The country is also considering strategies to make packaging producers responsible for the full cost of designing, producing, and discarding the packaging they place on the market (6) and a system in which consumers would pay a fee at the time of sale that would be reimbursed when they returned reusable packaging to a designated location (7).

In 2018, China's express delivery sector generated 8.8 million metric tons of packaging waste, and in 2020 the country shipped more than 80 billion plastic-wrapped parcels-the most in the world $(8,9)$. In March, the Chinese Ministry of Transport implemented a green packaging regulation to reduce over-wrapping and increase the use of green materials and recycling bins for packaging (10). Companies that do not comply with the regulations by using single-use plastic could be charged up to USD15,450 per violation.

Regulations like those in the United Kingdom and China are a step toward making producers responsible for their use of packaging products and encouraging more recycling-friendly plastic packaging (11). However, few companies have kept pace with previous legislation related to sustainability. A survey showed that $60 \%$ of global packaging companies reported no policies on key sustainable packaging-related topics (12). Legislation must be structured to make green strategies and sustainable products essential for packaging companies to maintain competitiveness and financial profitability. All countries, including the United Kingdom and China, should require the packaging industry to meet environmental, social, and governance standards for sustainability. Regulations should be written to include regular evaluations of companies' performance and hold those in violation accountable with fines or fees that are high enough to incentivize compliance.

Siming You ${ }^{1 *}$, Wangliang $\mathrm{Li}^{2}$, Wei-Cheng Yan ${ }^{3}$, Christian Sonne ${ }^{4}$

${ }^{1}$ University of Glasgow, Glasgow, UK. ${ }^{2}$ Institute of Process Engineering, Chinese Academy of Sciences, Beijing, China. ${ }^{3}$ Jiangsu University, Zhenjiang, China. ${ }^{4}$ Aarhus University, Roskilde, Denmark. ${ }^{*}$ Corresponding author: Email: siming.you@glasgow.ac.uk

REFERENCES AND NOTES

1. I. Tiseo, "Distribution of plastic waste generation worldwide in 2018, by sector," Statista (2020).

2. "Packaging waste by waste management operations," Eurostat (2021).

3. "The future of global packaging to 2024," Smithers (2019).

4. UK Department for Environment, Food \& Rural Affairs, "UK statistics on waste" (2020).

5. UK HM Revenue \& Customs, "Introduction of a new plastic packaging tax" (2020).

6. UK Department for Environment, Food \& Rural Affairs, "Packaging and packaging waste: Introducing extended producer responsibility" (2021).

7. UK Department for Environment, Food \& Rural Affairs, "Introducing a deposit return scheme in England, Wales and Northern Ireland" (2021).

8. P. Kang et al., Nat. Commun. 12, 1 (2021).

9. The State Council, People's Republic of China, "Country's express delivery business volume exceeds 80 billion in 2020" (2020); www.gov.cn/xinwen/202012/21/content 5571848.htm [in Chinese].

10. The State Council, People's Republic of China, "Regulations of mail and delivery packaging" (2021) www.gov.cn/zhengce/zhengceku/2021-02/25/content 5588767.htm [in Chinese]

11. S. A. Bassi et al., Resour. Conserv. Recycl. 162 105030 (2020).

12. G. Thoumi et al., "Unwrapping investor risk: Global plastic containers and packaging sector," Planet Tracker (2021).

10.1126/science.abj1042 